\title{
Digital human experience models for augmented reality mobile wellness devices
}

\author{
Pirita Ihamäki \\ Degree Program of Cultural Management and Landscape Studies, \\ University of Turku, \\ Siltapuistokatu 2, Pori, Finland \\ E-mail: Pirita.ihamaki@utu.fi
}

\begin{abstract}
Mobile wellness devices are popular in personal devices, which are used to maintain health during physical activities. This paper presents theoretical work on digital human experience models. The paper uses digital human experience models to improve the experiences that users have when they interact with mobile augmented reality devices. This paper uses user-centred design methods and results from previous studies to create digital human experience models, which can be used to capture, store, process and transmit information for mobile augmented reality wellness devices. The results showed that users can use the new augmented reality wellness devices more easily to store, process and transmit wellness information and to more easily manage their everyday lives. This paper creates the conceptual design of the digital human experience models, with experimental subjects. Future studies will create and test the complete digital human experience models (in software), with lead users.
\end{abstract}

Keywords: user-centred design methods; digital human experience models; augmented reality; mobile wellness devices.

Reference to this paper should be made as follows: Ihamäki, P. (2015) 'Digital human experience models for augmented reality mobile wellness devices', Int. J. Digital Human, Vol. 1, No. 1, pp.44-71.

Biographical notes: Pirita Ihamäki received her MA in Digital Culture from the University of Turku, Degree Programme Cultural Production and Landscape Studies in 2001 and MSc (Economy) in Marketing form Turku School of Economics in 2011. She is currently working in Rock My Business Ltd as a Concept Designer. From 2008 to 2010, she was a researcher in the Tampere University of Technology Unit of Human-Centered Technology. She is the author of two books, the author of more than 20 papers and she has presented papers in more than 30 conferences. Her research interests include digital culture, digital education applications, digital tourism applications and user-centred design.

\section{Introduction}

Digital human models are an emerging technology that combines computer-aided engineering design, human factors engineering and applied ergonomics to simulate human behaviours (Nauman and Rötting, 2007). Digital human experience models are digital human models that are used to create experiences for device users that simulate interactions with real humans. This paper employs user-centred design methods to create 
the conceptual designs of digital human experience models for mobile augmented reality (AR) wellness devices. The paper uses questionnaires and focus groups to develop plastic, clay, or paper models of AR wellness devices. The paper uses role-playing in outdoor environments to determine the experiences that experimental subjects have when using the plastic or paper models of AR wellness devices. The results showed that questionnaires, focus groups and role-playing can be used to identify important information elements for digital human experience models on AR wellness devices. The results can also be used to evaluate and improve user-centred design methods for AR wellness devices. By integrating dynamic simulations and detailed evaluations, the context assessments can also help system designers to visualise and improve real AR wellness devices (Lämkull et al., 2009). The distinct advantages of using the results to evaluate and improve user-centred design methods for AR wellness devices include the ability to perform AR wellness context assessments in the early design process and to improve communication and understanding of both user experiences and design alternatives. The paper describes the comparative experimental study, which was completed, the simulation results and the implications of the simulation results for real AR wellness devices. The simulation results focus on the experimental subjects' points-of-view, in response to the simulated AR wellness environments, in which the experimental subjects experienced simulated wellness interactions, which occurred in predetermined manners. The simulations used focus groups and role-playing methods to focus on and evaluate specific AR wellness interactions, which were related to specific wellness events, concepts and theories.

Performing physical activities is one of the most important factors in maintaining a state of wellbeing. During recent years, various mobile devices and applications have been developed, such as heart rate monitors and pedometers, which can be used to assist users when they are performing physical activities. The mobile devices and applications can be used to help users by giving social support, helping users to visualise perceived benefits, providing information or feedback about the physical activities, or helping users to set appropriate goals (Martin et al., 1984; Locke and Latham, 1985; Annesi, 1998; Laverie, 1998; Leslie et al., 1999; Paschali et al., 2005; Ahtinen et al., 2008). Some mobile devices and applications can, for example, provide feedback about physiological responses and also provide location information, which is essential for some sports and outdoor activities. In addition, some mobile devices and applications provide enhanced services on the internet. For example, Ahtinen et al. (2008) described a sports tracking application on a mobile phone, an associated enhanced sports tracking service on the internet and a user study in which 28 experimental subjects evaluated both the sports tracking application on the mobile phone and the associated enhanced sports tracking service on the internet.

Other papers describe various characteristics of mobile wellness devices and applications. For example, Ahtinen et al. (2008) and Yang et al. (2006) described system integration techniques, which are critical for developing mobile wellness devices and applications. Yang et al. (2006) and Höysniemi et al. (2004) developed a prototype interactive shadow-boxing game, which uses a web camera to detect body movements and uses the body movements to control the game. The paper showed that playing the game significantly increased most of the users' heart rates to optimal exercise levels (Höysniemi et al., 2004). Uematsu and Saito (2008) developed a visually enhanced interactive mixed reality (MR) bowling system. MR systems cover the extensive continuum between reality and virtual reality [Azuma, (1997), p.20]. In practice, MR 
systems are implemented as AR systems, in which a real world environment is augmented with digital (virtual) objects, or as augmented virtuality (AV) systems, in which a virtual environment is augmented with real objects. As a result, AR or AV systems use user interactions with both real and virtual objects to enhance user perceptions and experiences [Träskbäck, (2004), p.13].

In particular, AR wellness devices and applications use information and communication technology (ICT) to overcome the limitations of traditional wellness devices and applications by creating new and extended user perceptions and experiences in which the users' real environments are integrated with the devices' and applications' virtual environments. By integrating the real and virtual environments, AR wellness devices and applications can improve the social quality of traditional wellness devices and applications. Hence, a key aspect of AR wellness devices and applications is that they can fit seamlessly into the users' everyday lives and environments (Herbs et al., 2008). As a result, previous papers show that AR wellness devices and applications can provide rich, useful, delightful, positive and surprising user experiences. However, previous papers show that user experiences and acceptances of AR wellness devices and applications have not been studied sufficiently. For example, user-centred design approaches have been used to identify user requirements, contexts and tasks for many types of AR devices and applications. However, user-centred design approaches have not been used sufficiently to identify user requirements, contexts and tasks for AR mobile wellness devices and applications. Therefore, new user-centred design approaches are needed for AR mobile wellness devices and applications, because most AR devices and applications, for example, design systems or remote process control systems, are used in work environments, whereas AR mobile wellness devices and applications are used in leisure or outdoor environments (Olsson et al., 2009).

Socio-demographic shifts, health awareness, changes in consumers' behaviours and changes in consumers' values have also caused AR mobile wellness devices and applications to become more important in our social system and therefore also in the global market. The increasing demand for AR mobile wellness devices and applications calls for new innovative AR mobile wellness devices and applications which can be used to achieve a higher degree of wellness in spirit, mind and body (Poon, 1993; Weiermair, 2001). The new innovative AR mobile wellness devices and applications, which package and offer complete and holistic wellness services, are needed in the health, wellness, tourism and sports industries.

Wellness is defined in various ways. In 1961, Dr. Halbert Dunn developed the term 'wellness' as a composition of the words 'wellbeing' and 'fitness'. He called the condition of the human spirit, mind and body being in a state of great personal contentment 'high-level wellness' (Nahrstedt, 2004). Myers et al. (2000) defined wellness as a way of life, which pursues optimal health and well-being of the spirit, mind and body integrated and living in harmony with the human and natural community. Adams (2003) described the four main principles of wellness:

1 wellness is multi-dimensional

2 wellness research and practice should focus on identifying causes of wellness

3 wellness is about balance

4 wellness is relative, subjective, or perceptual. 
Therefore, wellness can be defined as a balanced state of spirit, mind and body, including the holistic aspects and dimensions of self-responsibility, physical fitness, beauty care, healthy nutrition, relaxation, mental activity and environmental sensitivity (Müller and Lanz-Kaufmann, 2001). Wellness can also help individuals 'find themselves' in an era of high stress. Wellness can be understood as a healthy and holistic outlook on life. The final goal of wellness is to achieve long-term feelings of contentment, rather than temporary feelings of happiness.

As a result, the goal of this paper is to improve AR mobile wellness devices and applications and in particular, user experiences on AR mobile wellness devices and applications. To achieve the goal, the paper aims to provide a clear and improved definition of AR mobile wellness devices and applications, which designers can use to create the new innovative AR mobile wellness devices and applications that are needed by users. The definition must describe the contexts, experiences and components of AR mobile wellness devices and applications. The definition must also and perhaps more importantly, describe the methods that can be used to design or script the contexts, experiences and components of AR mobile wellness devices and applications (Forlizzi, Ford, 2000). The focus of this paper is to describe methods that can be used to improve AR wellness devices and applications in the wellness industry. The paper thereby addresses the lack of previous studies on AR mobile wellness devices and applications in the wellness industry. In this study, AR mobile wellness devices and applications augment real world environments with virtual (digital) information in wellness contexts to improve life with respect to optimal health and well-being of the spirit, mind and body, in ways that integrate the individual and the natural community. Therefore, AR mobile wellness devices and applications are considered to be integrated devices and applications that offer full life-coaching services.

The paper describes the methods that can be used to design or script the contexts, experiences and components of AR mobile wellness devices and applications in three steps. First, the paper describes the user-centred design methods that can be used to capture, store, process and distribute user input. Second, the paper describes the focus group methods that can be used to simulate AR mobile wellness contexts and which can be evaluated using digital human experience models and theories. Third, the paper describes the role-playing methods that can be used to evaluate and modify the simulated AR mobile wellness devices and applications. The results showed that the methods can be effectively used to develop, simulate, evaluate and modify AR mobile wellness devices and applications. As a result, the paper develops collaborative design methods which, in this study, integrate experimental subjects and which, in future studies, integrate lead users into the design process for new innovative AR mobile wellness devices and applications, early in the design process.

\section{Digital human experience models}

Actual human experiences are anticipated, perceived, constructed, considered and evaluated. Experiences come into our consciousness and are shaped by the constructive activities of embodied, situated perception at the intersection of the intentional trajectories of anticipation and retrospection. Realistic models of time and experience have important implications for experiential systems, given their divergence from standard computational models of time as an ordered succession of discrete moments 
(Varela, 1999). Human experience models show that experience is not a thing - but a process - and, more particularly, a process that takes place in human minds and bodies. Actual human experiences are anticipated, perceived, constructed, considered and evaluated in the human mind. Therefore, experiences cannot be captured, stored and transmitted by devices. The experiences must be converted into information. From phenomenology, experiences are based upon and constructed from perspectives, which raises issues about how experiences are formed in the mind and how experiences and interpretations of experiences are communicated from one person to another (Davis, 2003). This paper uses questionnaires, focus groups and role-playing to communicate information about experiences and uses the information to create and evaluate digital human experience models for AR mobile wellness devices and applications. Therefore, the paper addresses both fundamental research issues related to how experiences are communicated and applied research issues related to developing human-machine systems and especially AR mobile wellness devices and applications. What is of paramount importance is that the experience models that designers use affect their design decisions. As a result, the primary goal of this paper is, at the fundamental level, to developing effective experience models and, at the applied level, to developing effective experience models for AR mobile wellness devices and applications. As a result, this paper describes the most common model of human communication that is used to design systems, identifies model limitations and proposes an alternative model of human communication, which can be used to design, in particular, AR mobile wellness devices and applications.

Figure 1 The conduit metaphor of human communication

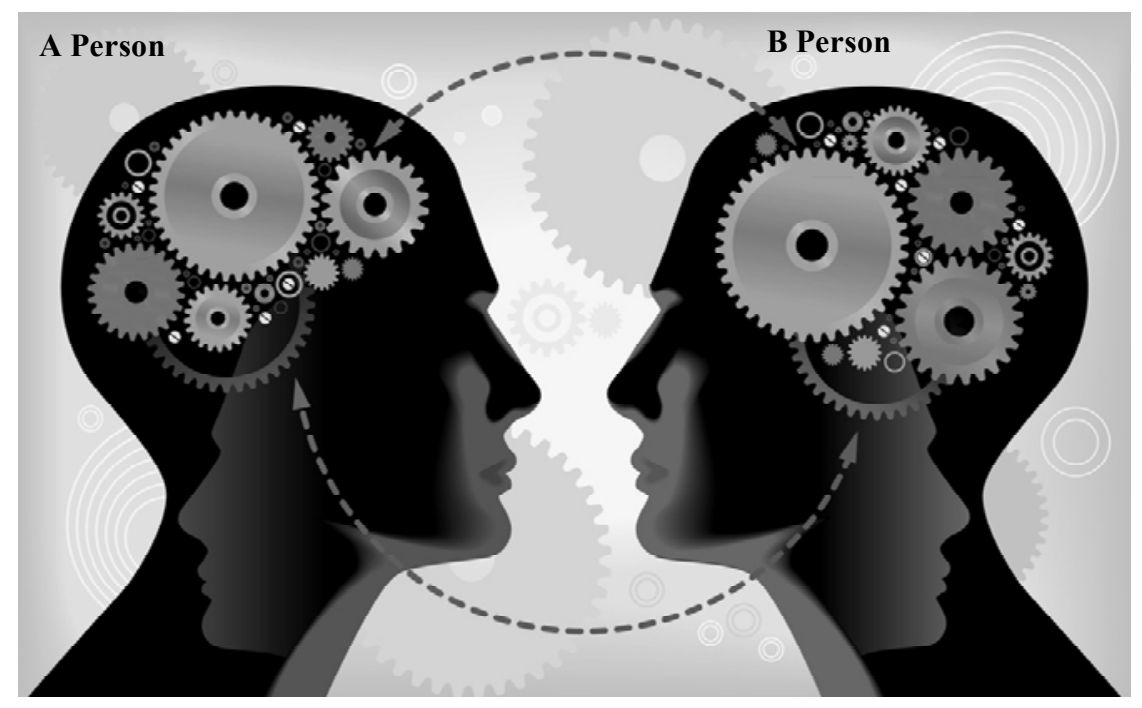

The conduit metaphor is the most common model of human communication that is used to design systems (Reddy, 1993). The conduit metaphor is a model of human thought, language and communication. As shown in Figure 1, the conduit metaphor models communication as a process of transferring thoughts from one person's mind to another person's mind through the conduit of language. 
According to Reddy (1993), the core assumptions of the conduit metaphor include:

- language functions like a conduit for transferring a person's thoughts or feelings to another person

- words are used to contain and transfer a person's thoughts or feelings to another person

- $\quad$ in writing or speaking, a person converts their thoughts or feelings into words

- in listening or reading, a person extracts the thoughts or feelings of another person from words

In the conduit metaphor, the thoughts or feelings that a person has in their mind are called repertoire members $(\mathrm{RM})$ and the written or spoken words that a person uses to communicate their thoughts or feelings to another person are signals (S) consequently, in the conduit metaphor, a person converts their thoughts or feelings RM into S, transfers $\mathrm{S}$ to another person and the other person receives S and extracts RM (Davis, 2003).

This paper extends the conduit metaphor to consider human experiences and feelings during the user-centred design process for AR mobile wellness devices and applications. The core assumptions of the extended model include:

- A person can transfer their previous experiences and expectations to another person in a focus group session by speaking or writing words into an external idea generation space.

- A person can combine words into narratives or stories, which can be modified or revised through conversations in the focus group sessions. The conversations provide means for transferring creative thoughts and feelings, which play an important role in the design process. The conversations give a person the ability to extend their thoughts or feelings and transfer their extended thoughts or feelings into the external idea generation space.

- A person can experience the extended thoughts or feelings through role playing.

As a result, this paper extends and applies the conduit metaphor to the user-centred design process for AR mobile wellness devices and applications. In particular, this paper analyses and develops methods for converting thoughts or feelings (RM) into signals (S), transferring signals (S) from one person to another person and extracting thoughts or feelings (RM) from signals (S), during the user-centred design process for AR mobile wellness devices and applications. Of particular interest to the authors, signals (S) cannot fully contain thoughts or feelings, just as information cannot fully describe experiences. A person's thoughts, feelings and experiences are a person's inner mental events. As such, they are not directly accessible and tangible to another person's mind. In addition, although helpful, the conduit metaphor assumes that communication is effortless and that communication breakdown, or having to work at understanding, is the exception, rather than rule. In fact, meanings and interpretations are negotiated, often hard-won, post-hoc constructions. In addition, communication breakdowns routinely occur between human beings and the process of dialogue is required to improve communication and transfer accurate representations of a person's thoughts or feelings. 
Therefore, the goal of this paper is to provide an improved alternative to the conduit metaphor, which recognises and focuses on the process of dialogue in the user-centred design process for AR mobile wellness devices and applications. Previous papers have provided general alternatives to the conduit metaphor. For example, Davis (2003) and Reddy (1993) provided general alternatives to the conduit metaphor, which focused on the process of dialog in human communication. This paper goes beyond the work of Davis (2003) and Reddy (1993) by creating a digital human model that focuses on the process of dialog that designers and users have when they design AR mobile wellness devices and applications that capture, store and transfer thoughts or feelings that real humans (coaches, physiotherapists, doctors, wellness professionals) transfer in their communications with the real humans that they interact with in their work. The digital human model uses user-centred design methods (questionnaires, focus groups) to capture wellness information and uses role playing to capture, store and transfer thoughts or feelings about AR mobile wellness devices.

\section{Methodology}

The goal of this paper, then, is to use digital human experience models to improve user-centred design processes for AR mobile wellness devices and applications, which can reduce design time, reduce development cost, improve product quality and enhance productivity. Companies already use user-centred design processes to improve product development processes, which can help them to face the challenges associated with developing products that are affected by the physical attributes and behaviours of humans. For example, companies use user-centred design processes to develop products that are human-centred, evaluate product development processes and consider human factors in product development processes, before building physical prototypes (Nauman and Rötting, 2007). The goal of this paper is to extend the use of user-cantered design processes by creating digital human experience models and using digital human experience models to improve product development processes for AR mobile wellness devices and applications. Consequently, this paper purposely develops a method for improving user-centred design processes, which consists of listening to lead users during product development processes and using their expectations and experiences to develop improved AR mobile wellness devices and applications. The method is concerned with incorporating lead users' perspectives into user-centred design processes in order to develop more useful and usable AR mobile wellness devices and applications. The method is intended to enhance previous user-centred design processes described, for example, by Maguire (2001), rather than to replace them.

The key principles of user-centred design processes are:

1 the active involvement of users

2 a clear understanding of the users and their task requirements

One of the key strengths of user-centred design processes is the active involvement of users who have knowledge concerning the contexts in which the devices and applications will be used. Involving users can also enhance the acceptance of and commitment to, the 
new devices and applications, since the users feel that the devices and applications are being designed in consultation with them, rather than being imposed upon them (Maguire, 2001). Strategies for involving users have been discussed in, for example, Damodaran (1996). According to Damodaran (1996), strategies that involve a small number of users can be effective for providing a detailed understanding of the users and their task requirements. As a result, this study included a total of 15 experimental subjects, who were all interested in using new AR mobile wellness devices and applications and who were used to represent the actual lead users who will be included in future studies. The reasons why a small number of experimental subjects were used in this paper were to collect a more detailed understanding of the experimental subjects and to successfully verify the research premises in a pilot study, before completing more extensive future studies, with actual lead users. The pilot study was used to reduce costs, reduce study times and gain quick access to new information about the best processes for developing AR mobile wellness devices and applications. However, product development teams, from more than one company, considered the findings from this paper to be useful for improving their user-centred design and product development processes.

User-centred design processes are also concerned with appropriate allocation of tasks between users and devices and applications. User-centred design processes must determine which tasks users will handle and which tasks devices and applications will handle. Task assignments should be based on an appreciation of human capabilities and limitations and a thorough grasp of the particular demands of the tasks (Maguire, 2001). Consequently, this paper used user-centred design processes (one primary questionnaire, two focus groups meetings, two role-playing dialog sessions and one evaluation questionnaire) to determine the users' capabilities and limitations and the particular demands of the tasks associated with using AR mobile wellness devices and applications. The paper used one primary questionnaire and two focus group meetings to determine the experimental subjects' technical-orientations and interests in the research study. The paper used two role playing dialog sessions to determine the experimental subjects' thoughts or feelings about AR mobile wellness devices and applications and the contexts in which AR mobile wellness devices and applications are used. One primary questionnaire, two focus group meetings and two role playing dialog sessions were used, because the experimental subjects could easily share their ideas and, as groups, quickly describe uses and contexts for AR mobile wellness devices and applications. The methods gave the experimental subjects opportunities to develop their own ideas concerning how they could use AR mobile wellness devices and applications, in practice.

User-centred design processes also use iteration to improve design solutions. Iteration generally consists of receiving feedback from users following their use of early design solutions. Early design solutions consist of prototypes that range from simple paper prototypes, to screen layouts, to software prototypes, with different levels of detail. Users attempt to use the prototypes to accomplish actual tasks (Maguire, 2001). The users' feedback is used to iteratively improve the design solutions. This paper used the focus group results to develop initial descriptions of AR mobile wellness devices and applications. The paper used two role playing dialog sessions to develop ideas for improving AR mobile wellness devices and applications. Designers could use the role playing results to improve the design solutions. 


\subsection{Participants}

The experimental design in this paper consisted of a simulated case study, which was conducted during 2010. The simulated case study was a simulated qualitative research study, based upon one primary enquiry (a questionnaire), two focus group meetings, two role-playing dialog sessions and one final evaluation enquiry (a questionnaire). In all, the case study used 15 experimental subjects to represent the actual lead users that will be used in future studies. The experimental subjects were grouped into two focus groups: the first focus group included six experimental subjects (three men and three women) and the second focus group included nine experimental subjects (two men and seven women). They were all between 20 and 55 years old. They were selected to include subjects that were interested in participating in the case study. The aim of the case study was to provide the experimental subjects with opportunities to dialog concerning different types of AR mobile wellness devices and applications and the contexts in which AR mobile wellness devices and applications are used.

\subsection{Primary enquiry}

The goal of the one primary enquiry (questionnaire) was to involve the experimental subjects in the user-centred design process for the AR mobile wellness devices and applications. In general, user-centred design processes use questionnaires to determine users' needs or requirements, their current work practices and their attitudes about new devices and applications, which can be used to complete work tasks. In general, the questionnaires are composed of a mix of closed-ended questions (which subjects answer by selecting fixed responses) and open-ended questions (which subjects answer by speaking or writing free-form responses). The questionnaires are particularly useful for collecting qualitative information about the users' needs or requirements, work tasks and their attitudes, which can be used to develop the intended devices and applications (Preece et al., 1994). In this paper, the user-centred design processes used questionnaires to determine the experimental subjects' needs or requirements, their current recreational activities and their attitudes about new devices and applications, which can be used to complete recreational activities. The questionnaire results showed that the experimental subjects participated in many different recreational activities, like martial arts, gymnastics, or physical exercise activities, for example, stretching or circuit exercise activities, running or cycling, snowboarding or alpine skiing (during the winter), or group exercise activities, for example, football, futsal, or volleyball (during the summer). Tables 1-2 show the different recreational activities, for the men and women in the first and second focus groups. 
Table 1 First focus group recreational activities

\begin{tabular}{lc}
\hline Men & Women \\
\hline Martial arts & Walking \\
Gymnastics & Running \\
& Martial arts \\
Running & Gymnastics \\
Walking & Alpine skiing \\
Gymnastics & \\
Swimming & \\
Gymnastics & Cycling \\
Running & Walking \\
\hline
\end{tabular}

Table 2 Second focus group recreational activities

\begin{tabular}{lc}
\hline Men & Women \\
\hline Volleyball and football & Riding, golf and snowboarding \\
Football & Cycling \\
Futsal & Running \\
Floorball & Gymnastics \\
Running & \\
Cycling & \\
Roller skating & \\
& Stretching exercises \\
& Cycling \\
& Walking \\
& Swimming \\
& Skiing \\
& Cycling \\
& Running \\
& Cycling \\
Swimming & Gymnastics \\
& Cycling. \\
& Gymnastics \\
& Nordic skiing \\
& Walking \\
& Running \\
& Exercises classes \\
& \\
& \\
& \\
& \\
& \\
& \\
& \\
& \\
&
\end{tabular}


Figures 2-3 show how often the experimental subjects participated in recreational activities. Tables 3-4 show how often the experimental subjects used mobile devices or applications in their recreational activities.

Figure 2 First focus group recreational activities (see online version for colours)

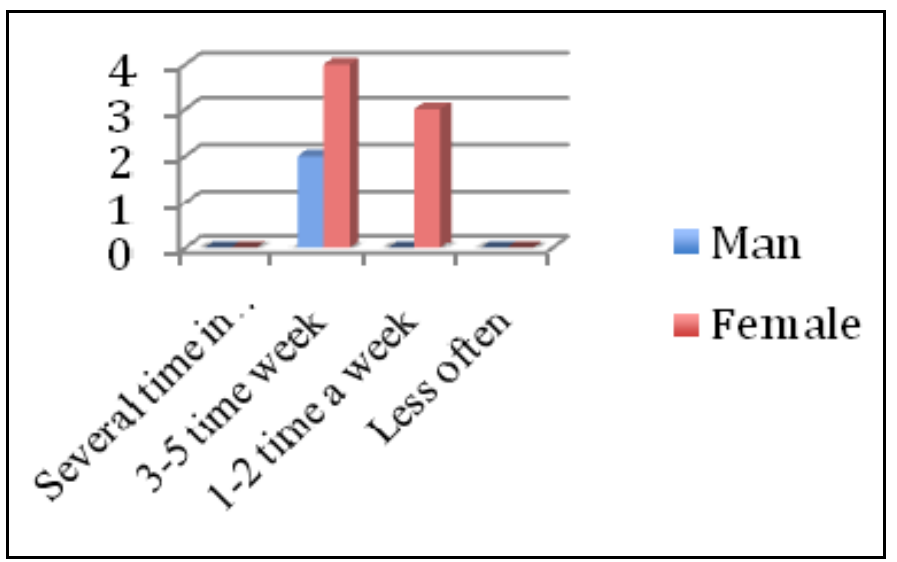

Figure 3 Second focus group recreational activities (see online version for colours)

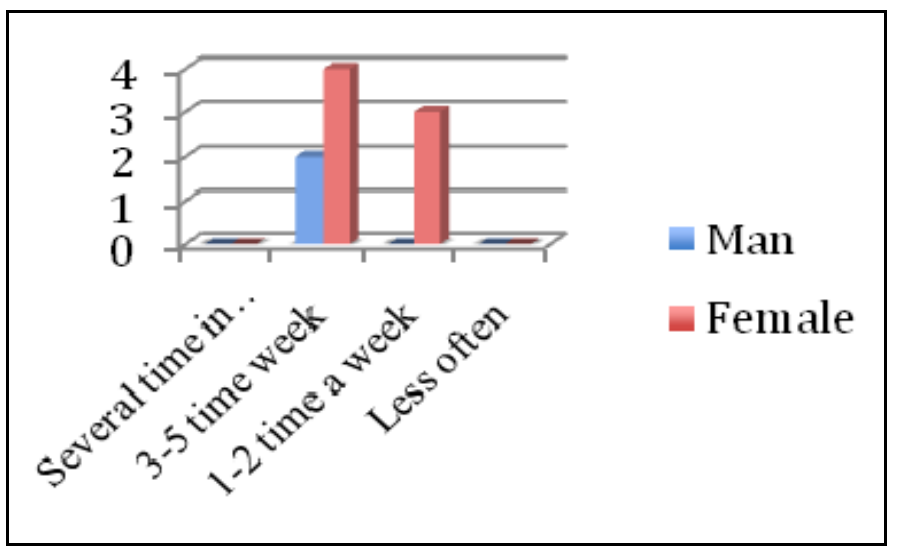

Table 3 First focus group recreational activities

\begin{tabular}{lccccc}
\hline Statements & Never & $\begin{array}{c}\text { Once or } \\
\text { twice }\end{array}$ & Monthly & Weekly & Daily \\
\hline $\begin{array}{l}\text { I use a sports tracker or similar } \\
\text { device in my activities }\end{array}$ & 5 & & 1 & \\
$\begin{array}{l}\text { I use other devices (mobile phones } \\
\text { or pedometers) in my activities }\end{array}$ & 2 & 3 & & 1 & \\
$\begin{array}{l}\text { I discuss my activities with others } \\
\text { on bulletin boards or similar systems }\end{array}$ & 5 & 1 & & 6 \\
$\begin{array}{l}\text { I would use new devices in my } \\
\text { activities }\end{array}$ & & & & \\
\hline
\end{tabular}


Table 4 Second focus group recreational activities

\begin{tabular}{lccccc}
\hline Statement & Never & $\begin{array}{c}\text { Once or } \\
\text { twice }\end{array}$ & Monthly & Weekly & Daily \\
\hline $\begin{array}{l}\text { I use a sports tracker or similar } \\
\text { device in my activities }\end{array}$ & 8 & 2 & & \\
$\begin{array}{l}\text { I use other devices (mobile phones } \\
\text { or pedometers) in my activities }\end{array}$ & 1 & 4 & 2 & 3 \\
$\begin{array}{l}\text { I discuss my activities with others } \\
\text { on bulletin boards or similar systems }\end{array}$ & 7 & 3 & & 1 \\
$\begin{array}{l}\text { I would use new devices in my } \\
\text { activities }\end{array}$ & & 1 & 9 \\
\hline
\end{tabular}

The primary enquiry presented four statements related to using mobile wellness devices or applications in recreational activities. The primary enquiry used a five-point Likert scale to determine how often the experimental subjects used mobile devices or applications in their recreational activities: never, once or twice, monthly, weekly, or daily (Likert, 1932). Consequently, the goal of the primary enquiry was to determine both the experimental subjects' present use of existing mobile wellness devices and applications in their recreational activities, as well as the experimental subjects' interest in using new mobile wellness devices and applications in their recreational activities.

The results showed that most of the experimental subjects did not use mobile wellness devices or applications extensively in their recreational activities. In the first focus group, five of the experimental subjects never used a sports tracker or similar device in their recreational activities. Only one of the experimental subjects used a sports tracker or similar device in their recreational activities. However, the one experimental subject only used a sports tracker or similar device in their recreational activities once per month. In the second focus group, eight of the experimental subject never used a sports tracker or similar device in their recreational activities. Two of the experimental subjects used a sports tracker or similar device in their recreational activities. However, the two experimental subjects only used a sports tracker or similar device in their recreational activities once or twice.

However, the results also show that the experimental subjects have a strong interest in using new mobile devices and applications in their recreational activities. In the first focus group, six of the experimental subjects would use new mobile devices and applications weekly. In the second focus group, nine of the experimental subjects would use new mobile devices and applications weekly. Consequently, the results showed that the experimental subjects did not find existing mobile devices and applications useful or usable. However, the results showed that the experimental subjects would like to use new mobile devices and applications in their recreational activities. Therefore, a primary goal of the study in this paper is to build a positive impression of mobile devices and applications for recreational activities.

\subsection{Focus group meetings}

The goal of the two focus group meetings was to give the experimental subjects opportunities to present and discuss their needs or requirements for AR mobile wellness devices and applications. As a result, the focus group meetings were qualitative studies, 
which used observational methods to determine the experimental subjects' needs or requirements for AR mobile wellness devices and applications, from the results of their discussions during the meetings. The focus group meetings were conducted in a Tampere University of Technology meeting room. Multiple data collection methods, which are commonly used in human-computer interaction studies, were used to collect the observations (Nielsen, 1993a, 1993b). The data collection methods are typically used to collect observations of focus groups, which consist of experimental subjects who represent actual lead users or who are actual lead users (Kitzinger, 1995). Previous studies showed that the data collection methods are useful for determining the experimental subjects' needs or requirements for human-computer interaction devices.

The two focus group meetings were completed by two researchers and two moderators describing the research context (AR wellness devices and applications), the two researchers and moderators describing results from previous research papers (using pictures and videos) and 15 experimental subjects (six men and nine women, with ages between 20-55 years), providing their needs and requirements for AR mobile wellness devices and applications. The experimental subjects in the first focus group meeting provided 19 needs and requirements and the experimental subjects in the second focus group meeting provided 18 needs and requirements. The two focus group meetings were held in August, 2010. Each focus group meeting was held for three hours on a first day and two hours on a second day.

The experimental subjects worked in pairs to provide needs and requirements. The purpose for working in pairs was to stimulate discussions and provide more needs and requirements (Maguire, 2001). Every experimental subject ranked all of the needs and requirements on five-point Likert scales. The rankings were used to determine the experimental subjects' attitudes and strengths of attitudes concerning all of the needs and requirements: strongly agree, agree, neither agree nor disagree, disagree, or strongly disagree (Likert, 1932). According to Albaum (1997), opinions are verbal expressions of attitudes, which must be either constructed within or retrieved from the minds of persons and which can therefore be used to measure the attitudes of persons. As a result, the methods used in the two focus group meetings were based upon the theoretical premises of attitude expression, measurement and evaluation presented by Likert (1932) and Albaum (1997). Tables 5-6 show the results from the two focus group meetings, which are the experimental subjects' needs and requirements for AR mobile wellness devices and applications. Designers also evaluated the quality of the needs and requirements from the two focus group meetings.

Table 5 First focus group needs and requirements, with average attitudes

\begin{tabular}{llr}
\hline Need & \multicolumn{1}{c}{ Description } & Attitude \\
\hline 1 & $\begin{array}{l}\text { A travel guide that provides routes and destinations which promote wellness } \\
\text { during vacations. }\end{array}$ & 5.0 \\
2 & $\begin{array}{l}\text { A doctor that monitors, tracks, documents and helps to overcome poor } \\
\text { wellness conditions. }\end{array}$ & 4.8 \\
3 & $\begin{array}{l}\text { A motivator that praises, encourages and rewards positive wellness } \\
\text { conditions. }\end{array}$ & 4.7 \\
4 & $\begin{array}{l}\text { A teacher that accesses, screens and provides suitable wellness information. } \\
5\end{array}$ & $\begin{array}{l}\text { An accountant that monitors, calculates, makes payments and learns user } \\
\text { preferences to achieve and maintain positive financial conditions. }\end{array}$ \\
\end{tabular}


Table 5 First focus group needs and requirements, with average attitudes (continued)

\begin{tabular}{|c|c|c|}
\hline Need & Description & Attitude \\
\hline 6 & $\begin{array}{l}\text { A coach that gives instructions, proposes new actions and provides feedback } \\
\text { during recreational activities. }\end{array}$ & 4.5 \\
\hline 7 & $\begin{array}{l}\text { A nutritionist that provides information and helps control nutritional } \\
\text { wellness. }\end{array}$ & 4.3 \\
\hline 8 & $\begin{array}{l}\text { A coach that helps to match physical activity levels to nutritional and caloric } \\
\text { need levels }\end{array}$ & 4.0 \\
\hline 9 & $\begin{array}{l}\text { A locator that finds friends that are involved in the same physical activities } \\
\text { at the same time. }\end{array}$ & 4.0 \\
\hline 10 & A wellness device that is always on (always available to help). & 4.0 \\
\hline 11 & A matchmaker that helps to find suitable friends. & 3.8 \\
\hline 12 & $\begin{array}{l}\text { A wellness device that let's you share information about your recreational } \\
\text { activities with friends and compete with friends. }\end{array}$ & 3.8 \\
\hline 13 & $\begin{array}{l}\text { Virtual characters that represent trainers, users, or friends, which can } \\
\text { interact with each other, which can be used to visualise physical activities or } \\
\text { interpersonal interactions and which adapt to have the same physical } \\
\text { characteristics, interests and spirits of the persons they represent, }\end{array}$ & 3.7 \\
\hline 14 & $\begin{array}{l}\text { A visible coach that can demonstrate actions, provide alternatives and guide } \\
\text { performances, as well as provide numerical information (times, heart rates, } \\
\text { distances) and track long-term effects (training effects or physical gains). }\end{array}$ & 3.7 \\
\hline 15 & $\begin{array}{l}\text { A personal trainer that provides incentives and controls diet and overall } \\
\text { health and wellness conditions. }\end{array}$ & 3.5 \\
\hline 16 & $\begin{array}{l}\text { A wellness device that lets users control their virtual environments: use } \\
\text { HUDs, parallel operation, compete with a virtual person and change the } \\
\text { environment to different locations. }\end{array}$ & 3.2 \\
\hline 17 & $\begin{array}{l}\text { An automatic coach that can automatically create a training programme to } \\
\text { achieve a rehabilitation or wellness goal. }\end{array}$ & 3.0 \\
\hline
\end{tabular}

Table 6 Second focus group needs and requirements, with average attitudes

\begin{tabular}{llc}
\hline Need & \multicolumn{1}{c}{ Description } & Attitude \\
\hline 1 & $\begin{array}{l}\text { A wellness device that can be used to select and balance exercise and diet, } \\
\text { create menu plans and be used to listen to music, which includes interactive } \\
\text { monitoring, incentives and a user-friendly interface. }\end{array}$ & 5.0 \\
2 & $\begin{array}{l}\text { A wellness device that includes games associated with the user's } \\
\text { recreational activities, which can be used to motivate and increase physical } \\
\text { movements. }\end{array}$ & 4.7 \\
& $\begin{array}{l}\text { A workout assistant that can find good gyms or running routes when } \\
\text { travelling and which enhances and promotes wellness activities by } \\
\text { providing incentives, such as creating bird song sounds, creates personal } \\
\text { profiles and tracks personal progress. }\end{array}$ & 4.5 \\
& $\begin{array}{l}\text { A wellness device that can be used for life management: financial } \\
\text { expenditures, event schedules and interest information, with an advanced } \\
\text { interactive calendar that includes and tracks alertness levels, physical } \\
\text { activities and nutrition information, which can project information to } \\
\text { different devices: car display, glasses, cell phone, television, or walls. }\end{array}$ & 4.3 \\
& & \\
\hline
\end{tabular}


Table 6 Second focus group needs and requirements, with average attitudes

\begin{tabular}{|c|c|c|}
\hline Need & Description & Attitude \\
\hline 5 & $\begin{array}{l}\text { A virtual motivator and coach that can encourage users in gym } \\
\text { environments, link to gym equipment and provide information: number of } \\
\text { repetitions, weights and heart rates. }\end{array}$ & 4.1 \\
\hline 6 & $\begin{array}{l}\text { A workout nutritionist that can recommend both foods and supplements and } \\
\text { link to online shops that sell the foods and supplements with discounts, to } \\
\text { improve personal diet and health, }\end{array}$ & 4.0 \\
\hline 7 & $\begin{array}{l}\text { A wellness device that promotes wellness in nutrition, physical activities } \\
\text { and cultural integration, which provides food and nutrition services and } \\
\text { menus for specific days, provides recipes, provides ingredient acquisition } \\
\text { alternatives, sets rules, selects facilities, chooses optimal training times, } \\
\text { calculates energy expenditures, structures weight-loss programmes, sets } \\
\text { training intensities, recommends physical therapy programmes, provides } \\
\text { virtual competitors that encourage training and ranks options, based on } \\
\text { personal needs and the opinions of others. }\end{array}$ & 4.0 \\
\hline 8 & $\begin{array}{l}\text { A wellness device that travellers can use to maintain goal-oriented physical } \\
\text { activities, as well as monitor and maintain healthy diets, when travelling. }\end{array}$ & 3.8 \\
\hline 9 & $\begin{array}{l}\text { A mobile coach that can be used to plan exercise programmes in advance } \\
\text { and provide music or rhythms to enhance performance during exercise } \\
\text { activities. }\end{array}$ & 3.8 \\
\hline 10 & $\begin{array}{l}\text { A wellness devices that includes a calendar, recommends times for sports } \\
\text { activities one or two times per day, with options for light or heavy exercise, } \\
\text { which also considers weather conditions, selects routes based on physical } \\
\text { condition, topography, environment (urban, forest, track, road), distance and } \\
\text { facilities (sports news services, private sports centres, gyms, or clubs) and } \\
\text { safety. }\end{array}$ & 3.6 \\
\hline 11 & $\begin{array}{l}\text { A mobile coach that provides music, heart rate feedback and objectives as } \\
\text { incentives. }\end{array}$ & 3.5 \\
\hline 12 & $\begin{array}{l}\text { A wellness device that has sensors which can be used to automatically } \\
\text { collect physical and exercise information. }\end{array}$ & 3.5 \\
\hline 13 & $\begin{array}{l}\text { An integrated wellness device that includes a phone and applications: a } \\
\text { heart rate monitor and a programme that can find and recommend sports } \\
\text { facilities. }\end{array}$ & 3.5 \\
\hline
\end{tabular}

The results from the two focus group meetings can be used to create AR mobile wellness devices and applications. The results showed that users need AR mobile wellness devices that include virtual reality characters who represent doctors, trainers, motivators and travel advisors who can automatically offer advice, create training programmes, encourage and provide incentives and that can also be used to interact with and share information with friends (via phone connections or social media tools). Consequently, the results from the two focus group meetings show that focus group meetings can be used to improve the conduit metaphor of human communication, user-centred design processes for AR mobile wellness devices and the digital human experience models that are used to create AR mobile wellness devices. 


\subsection{Role-playing dialog sessions}

The goal of the two role-playing dialog sessions was to give the experimental subjects opportunities to incorporate their individual concepts into the designs for AR mobile wellness devices and applications. As a result, the two role-playing dialog sessions were a particularly important part of the user-centred design process for AR mobile wellness devices and applications. The two role-playing dialog sessions made it possible to incorporate the experimental subjects' concepts into designs, early in the design process (Svanaes and Seland, 2004).

Previous studies have also used role playing dialog sessions to create designs. For example, Iacucci et al. (2000) used dramas to develop product concepts, conduct research, communicate needs and test ideas. Binder (1999) used role playing dialog sessions to give experimental subjects opportunities to develop ideas about how they could use different AR mobile wellness devices and applications in their daily work. Binder (1999) used role playing dialog sessions to improve ideas from focus group meetings, by using pairs of experimental subjects to further develop, enrich and consolidate the ideas through discussions and shared experiences. Dewey (1980) showed that role playing dialog sessions can be used to provide user experiences that are generally unique, productive and enjoyable, in a manner that is similar to enjoying art.

As a result, in this paper, the role playing dialog sessions were used to further develop, enrich and consolidate the experimental subjects' needs and requirements, from the focus group meetings. In the focus group meetings, large groups developed and evaluated needs and requirements. In the role playing dialog sessions, three-person groups developed narratives about devices, situations and contexts, through extended discussions and dynamic interactions, which were related to the preliminary concepts developed in the focus group meetings. Consequently, the role playing dialog sessions were based upon the research concept that small group interactions can be used to enrich and develop product concepts (Merton et al., 1956; Morgan, 1988). The role playing dialog sessions were also based upon the research concept that role playing experiences are subjective events that can be used to engage product users in the design process, stimulate their memories of past experiences and envision, to some extent, future experiences (Sanders, 2001). In other words, role playing experiences are events in which memories and imagination meet.

In this paper, the experimental subjects used their own experiences with recreational activities and wellness devices and applications and mental associations to develop new ideas for developing AR mobile wellness devices and applications. The experimental subjects expressed their ideas in narratives or stories about new AR mobile wellness devices and how they would use the new AR mobile wellness devices in the contexts of their recreational activities. The experimental subjects both developed narratives or stories about the new AR wellness devices and applications and acted out the narratives or stories on the Tampere University of Technology campus. The experimental subjects also took notes about the narratives or stories, which other experimental subjects acted out. Consequently, the role playing dialog sessions were similar to the role playing dialog sessions in Buchenau and Suri (2000), in which product designers and product users acted out different situations related to the products. 
The role playing dialog sessions in this paper consisted of two days of discussions and role playing events. On the first day, the experimental subjects developed narratives or stories about how their envisioned AR mobile wellness devices worked. On the second day, the experimental subjects developed prototypes of their envisioned AR mobile wellness devices and used the prototypes in role playing events, to act out their narratives or stories. The experimental subjects used paper and pencils to develop their narratives or stories and used modelling clay and construction paper to develop their prototypes. The experimental subjects worked in groups of three and wrote their narratives or stories in their native language (Finnish). Consequently, the role playing dialog sessions were both collaborative learning and collective design events. In general, collaborative learning and collective design events are considered to be learning and design by social means, in which technology is both designed and used to encourage and mediate social interactions.

Therefore, the role playing dialog sessions were used to accomplish five main things: to understand the users, to understand the contexts, to explore new ideas, to evaluate new ideas and to communicate new ideas. The role playing dialog sessions were also used to provide some indication of the usefulness of the role playing dialog sessions in the product development process and usefulness of the AR mobile wellness devices and applications developed by using the role playing dialog sessions. The results showed that the role-playing dialog sessions can be used to guide development of the AR mobile wellness devices and applications, in various stages of the product development process, while considering a number of factors: the users, the contexts and the previous research results. The role playing dialog sessions are particularly useful for improving the product development process for AR wellness devices and applications, because the role playing dialog sessions give users opportunities to provide feedback in imaginary situations while using prototypes of the intended AR wellness devices and applications (Seland, 2006).

The role playing dialog sessions gave the experimental subjects concrete experiences with the prototypes, in realistic contexts. As a result, the role playing dialog sessions were effective at incorporating the experimental subjects' needs and requirements into the product development process. The role playing dialog sessions had the advantages of group work, interactive design methods, collaborative design efforts and useful design results. Consequently, through the act of completing the role playing dialog sessions, the experimental subjects both developed and iteratively refined and improved the designs of the AR mobile wellness devices and applications by themselves. In addition, the role playing dialog sessions had the advantage of developing both the designs for the AR mobile wellness devices and applications and the digital human experience models used by the AR mobile wellness devices and applications. Previous studies, used role playing dialog sessions that included both designers and users to create product designs (Brand and Grunnet, 2000). This paper used role playing dialog sessions that included experimental subjects that represented focus group users to create product designs. Therefore, the role playing dialog sessions in this paper were more user-centred than the role playing dialog sessions in previous studies. As a result, the role playing dialog sessions in this study improved the process of capturing the experimental subjects' needs, requirements and experiences, compared to the role playing dialog sessions in previous studies. The role playing dialog sessions in this paper also used the experimental subjects' evaluation capabilities and creativity more effectively than the role playing dialog sessions in previous studies.

The role playing dialog sessions in this paper were also structured to provide pleasant experiences in different contexts, which is important in role playing events (Buchenau 
and Suri, 2000). In particular, the experimental subjects were given opportunities to write and act out their own narratives or stories about the AR mobile wellness devices, as well as to reflect about their experiences during their role playing events. The results showed that the experimental subjects felt that the role playing dialog sessions were a good way to develop AR mobile wellness devices and applications and the digital human experience models used on the AR mobile wellness devices and applications. The following are actual narratives or stories, which were developed by the experimental subjects:

Running Buddy:

Bob is jogging while using a virtual coach program and wearing virtual glasses. He runs the program, which automatically selects a route situated in the town called Tampere in the neighborhood called Hervanta, which has a small lake. The virtual coach program continuously updates information on his heart rate, respiratory rate, and running speed, as well as the suitability of the exercise level for Bob. Before completing the route, Bob asks the virtual coach to contact Ben, a good friend of his. Ben is currently on a business trip in California, but the virtual coach can include Ben in his jog. With virtual glasses, it looks like Bob and Ben are jogging together, because there is a virtual character than looks like Ben. In fact, Ben is actually jogging on a treadmill in a gym. However, Bob and Ben can use the virtual coach program to customize their characters, talk to each other, and see the environment where Bob is jogging. Bob and Ben can also use the virtual coach program to see how much longer the jog will last. Bob and Ben can also choose videos or music to play during their jog, and to see updated information on alternative routes and levels of fitness needed to complete the alternative routes.

The Running Buddy narrative or story focuses on social interaction while jogging on actual paths in the outdoors or on treadmills in gyms. The Running Buddy narrative or story includes virtual technology, determines the experimental subjects' requirements or needs for AR wellness devices and applications and provides information that can be used to develop actual AR wellness devices and applications. The Running Buddy narrative or story shows that the role playing dialog sessions can be used to improve the user-centred design process for AR mobile wellness devices and applications.
Shopping:
Dylan arrives at a grocery store and he is very hungry. As usual, Dylan starts at the vegetable department. A virtual trainer pops up on Dylan's AR mobile wellness device, shows his shopping cart contents and the nutritional values of each item, and then praises him for his selections. The virtual trainer also proposes other products that increase wellness, which Dylan can put in his shopping cart. At the meat counter, Dylan thinks about making some grilled meat, but the virtual coach tells him that the meat contains too much fat and recommends healthier products instead. As Dylan gathers more items, the virtual trainer keeps track of the items, the nutritional values of the items, and shows Dylan how healthy the items are. At the check-out counter, Dylan wants to buy an item that is not healthy for him. The virtual trainer reminds Dylan that he entered his desire to no longer buy the item two months ago. Dylan struggles with his decision, but finally decides to not buy the item and buys a different item instead.

The Shopping narrative or story focuses on providing purchasing advice when shopping for groceries. The purpose of the narrative or story is to direct shoppers to buy healthy items. 
Mental Well-Being Coach:

Michael has a Mental Well-Being Coach. His Mental Well-Being Coach includes an AR mobile wellness device and application, with a virtual reality headset. When Michael wakes up in the morning his Mental Well-Being Coach appears on his AR mobile wellness device, to greet him and encourage him. His Mental Well-Being Coach says, "You look great today! I remember that you have an important meeting this afternoon. I know that you will do well. You have good ideas!" Michael goes to work. A couple of hours later, his Mental Well-Being Coach reminds him that it is time to take a break and relax. Michael uses his wellness application on his computer and his virtual reality headset to view a pleasant landscape. His Mental Well-Being Coach reminds him to "Relax. Take a deep breath. Every breath you take is a relaxing rush in and a pleasant rush out." Before his meeting, Michael starts to feel nervous, and he shuffles his feet. His Mental Well-Being Coach notices his body movements and heart rate, and tries to calm him down "Life moves forward. You can face every challenge. Your meeting will go well." Michael does well in his meeting. In the evening, Michael goes home and goes to rest. His Mental Well-Being Coach turns on the radio and finds some relaxing music.

The mental well-being coach narrative or story focuses on maintaining a positive and healthy state of mind, by providing encouraging and relaxing comments throughout the day, particularly at work.

Social Mobility:

Martin is a competitive athlete who uses a mobile coach to make training schedules and measure his performance. When he goes to a gym to do circuit training, he looks at his performance during the past month. He also uses his mobile coach to choose a friend to compete with. His friend, Martin, lives in London, but they can use their mobile coaches to do the same circuit training, at the same time, talk to each other during their workouts, and compare their performances after their workouts. After his workout, Michael decides to take a walk, so he uses his mobile coach to find someone in his gym that also wants to take a walk. He finds a friend that wants to take a walk with him, and the two friends go out for a walk together.

The Social Mobility narrative or story focuses on finding friends for mutual training or recreational activities.

\section{Your Life-Interactivity:}

Bob wants to be in the social scene, so he wants to buy a Your Life AR mobile wellness device and application. All of his friends have one, and the Your Life AR mobile wellness device and application have communication features, for example YouTube and Facebook. So he can use the Your Life AR mobile wellness device and application to contact his friends. He wants to talk to his friends about their recreational activities. The Your Life AR mobile wellness device and application also award points for reaching training goals, which can be redeemed for awards, such free ringtones or free training applications. In addition, the Your Life AR mobile wellness device and application have satellite navigation capabilities that he can use to track his friends, contact them, and ask them for advice concerning their recreational activities, for example, advice concerning good trainers for their recreational activities.

The Your Life - Interactivity narrative or story focuses on connecting with friends about their recreational activities. 


\section{Your Life-Management:}

James and his wife will soon have twins. Their life will be busy with two young children, so James and his wife decide to by a Your Life AR mobile wellness device and application. They want to use the Your Life AR mobile wellness device and application to plan their schedules. They can use their Your Life AR mobile wellness device and application to choose cultural events or recreational activities that are good for families. They can use their Your Life AR mobile wellness device and application to find babysitters or ask their friends about childcare options. They can also use their Your Life AR mobile wellness device and application to make sure they get enough sleep and relaxation. The Your Life AR mobile wellness device and application can send reminders to their mobile phones, $\mathrm{TV}$, or car monitor.

The focus of the Your Life - Management narrative or story is life management, including personal schedules and information about cultural events or recreational activities, babysitters or childcare options and sleep and relaxation.

Figure 4 A role-playing dialog session used to describe how an AR wellness device works (see online version for colours)

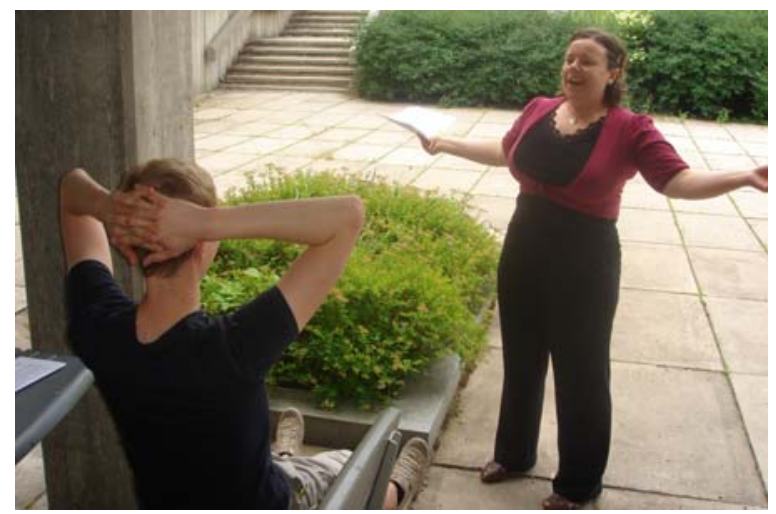

Figure 5 A role-playing dialog session used to describe how an AR wellness device with VR glasses works (see online version for colours)

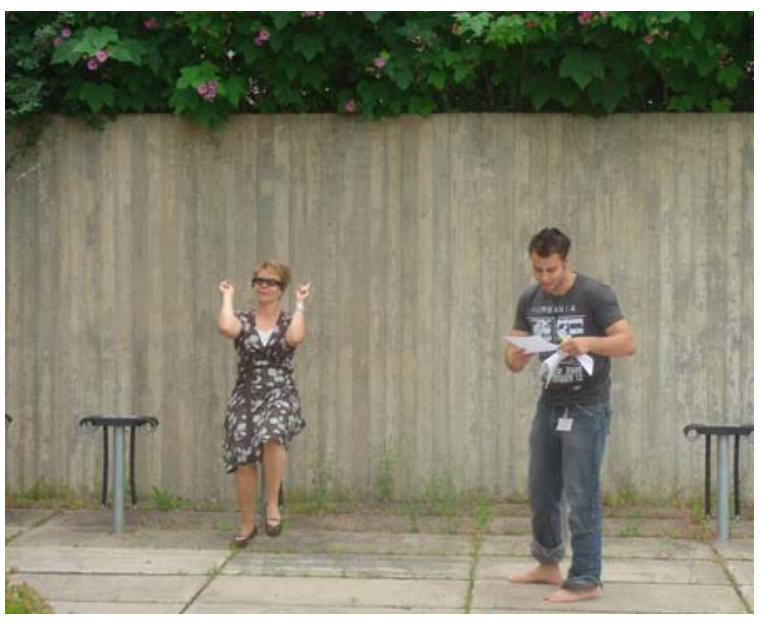


Figure 6 Early prototype of an AR wellness device which is worn on the wrist (see online version for colours)

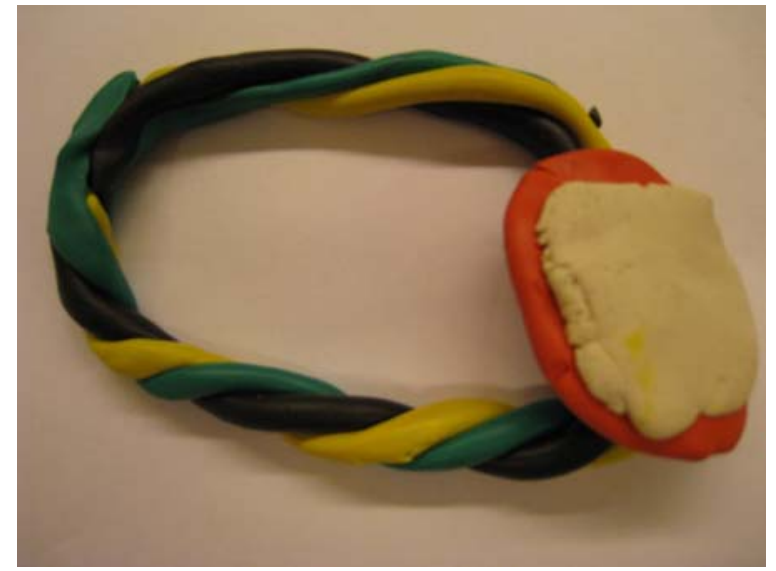

Figure 7 Early prototype of an AR wellness device which is held in the hand (see online version for colours)

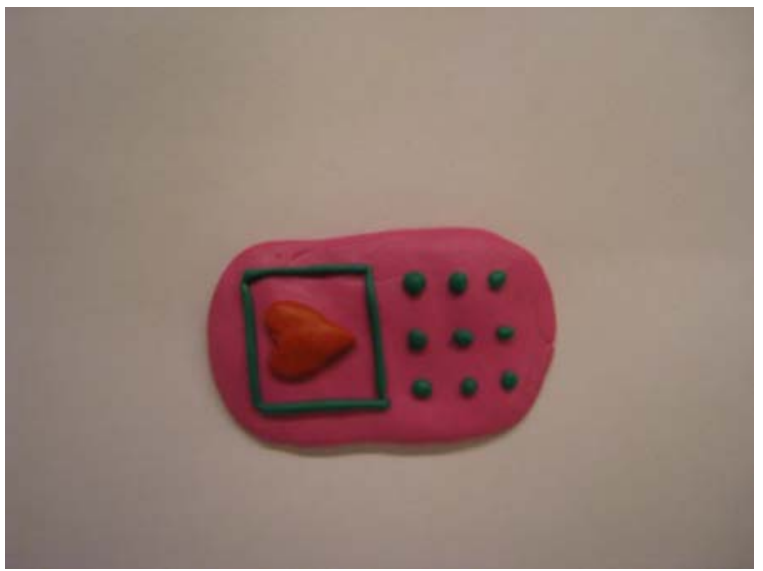

Figures 4-7 show examples of the role-playing dialog sessions that were used to develop early prototypes of AR mobile wellness devices and some of the early prototypes of AR mobile wellness devices which were created during the role-playing dialog sessions. The results showed that the experimental subjects thought that they could use AR mobile wellness devices for training, recreational activities, communication with friends, diet advice, mental well-being and life management. The results showed that the experimental subjects used the role playing dialog sessions to expand and enrich their ideas from the focus group meetings. All of the narratives or stories focused on finding information, making choices and taking actions, which promote healthy lifestyles. Most of the narratives or stories focused on improving athletic performance, work performance, or life management. The results showed that the digital human experience models used to create AR mobile wellness devices and applications should focus on the specific facilitating behaviours, rather than the specific personalities or personal characteristics of 
the actual doctors, trainers, motivators and travel advisors they represent. The results can be used to develop actual AR mobile wellness devices and applications.

\subsection{Final evaluation enquiry}

The goal of the final evaluation enquiry was to refine the ideas that were developed in the focus group meetings and role playing dialog sessions. The focus group meetings were used to develop initial ideas about AR mobile wellness devices and applications (Peat and Willett, 1991). The role playing dialog sessions were used to expand and enrich the ideas from the focus group meetings. The final evaluation enquiry used the following questions to refine the ideas that were developed in the focus group meetings and role playing dialog sessions:

- Were the ideas which were developed in the focus group meetings simple and meaningful to you?

- Did the focus group meetings follow the assessment guide format?

- Did working in pairs give you an opportunity to express your ideas?

- Did your focus group try to refine and select the best ideas?

- Was it easy to develop narratives or stories in the role playing dialog sessions?

- Did the role playing dialog sessions work for expanding and enriching ideas about AR mobile wellness devices and applications?

- Did the role playing dialog sessions follow the assessment guide format?

- How did the product development process work, as a whole?

- Which experiences in the product development process were good?

- Which experiences in the product development process were not good?

- How can AR mobile wellness devices and applications be used in the future?

- What will limit the use of AR mobile wellness devices and applications in the future?

- Do you have any other ideas about developing or using AR mobile wellness devices and applications?

The questions were used to determine the experimental subjects' thoughts or feelings about AR mobile wellness devices and applications and the product development process that was used to develop ideas about AR mobile wellness devices and applications. The results can be used to develop a list of the most important requirements or needs for AR mobile wellness devices and applications. The results showed that the experimental subjects thought or felt that the product development process that was used to develop ideas about AR mobile wellness devices and applications made it easy to develop AR mobile wellness devices and applications that they 'want to use and already need'. The results showed that the experimental subjects had strong thoughts of feelings about AR mobile wellness devices. The results showed that the product development process can be used to develop a list of requirements or needs for AR mobile wellness devices and 
applications and to also shape the experimental subjects' ideas about AR mobile wellness devices and applications.

\section{Discussion}

In this paper, the processes and models that were used to develop ideas about AR mobile wellness devices and applications were based upon the concept of "learning by doing" (Arrow, 1962). In the 'learning by doing' processes or models, the experimental subjects' were presented with problems or questions that they had to solve or answer. In general, problem solving is a skill that can be improved with practice. Therefore, in the "learning by doing" processes and models, the experimental subjects were given four different structured opportunities to practice and improve their problem solving skills: a primary enquiry (questionnaire), focus group meetings, role playing dialog sessions and a final evaluation enquiry (questionnaire). The problem solving opportunities were used to improve the user-centred design processes and the digital human experience models used to develop AR mobile wellness devices and applications. The results showed that the user-centred design processes and the digital human experience models were both effective and economical processes and models that product developers could use when:

1 they face heterogeneous demand for a given type of product or service and many of the users place a high value on customised solutions

2 outsourced design activities are high

3 the use of application-specific user information by the product developers is high

4 the use of application-specific user information by the suppliers is low (von Hippel, 1998).

The processes and models used in this paper expanded and enriched the conduit metaphor for developing AR mobile wellness devices and applications. The processes and models in the paper used a primary enquiry (questionnaire) to involve the experimental subjects in the user-centred design processes for the AR mobile wellness devices and applications, used focus group meetings to give the experimental subjects opportunities to present and discuss their needs or requirements for AR mobile wellness devices and applications, used role playing dialog sessions to give the experimental subjects opportunities to incorporate their individual concepts into the designs for AR mobile wellness devices and applications and used a final evaluation enquiry to refine the ideas that were developed in the focus group meetings and role playing dialog sessions. Therefore, the processes and models in this paper were used to transfer the experimental subjects' thoughts or feelings from one person to another person, to expand upon and enrich their thoughts and feelings and finally to refine their thoughts and feelings by speaking or writing into an 'idea generation space'. The results showed that the processes and models could be used to develop a rich set of ideas about AR mobile wellness devices and applications and to expand upon the experimental subjects' experiences, in simulated role playing dialog sessions. 


\subsection{Users as designers}

The results showed that there are advantages to using users as designers. Users know what their requirements or needs are. They can help to design products that they need and want. In this paper, the results showed that the experimental subjects needed or wanted AR mobile wellness devices and applications that they could use to monitor and instruct them concerning training, diet, schedule and mental well-being. The results showed that the experimental subjects needed or wanted AR mobile wellness devices and applications that were motivators and that offered rewards for their wellness achievements. In other words, the results showed that the experimental subjects needed or wanted AR mobile wellness devices and applications that offered a broad range of wellness services, especially when the experimental subjects were faced with new environments (such as when travelling) or when faced with new situations (such as when having twins). In new environments or new situations, the experimental subjects needed or wanted mental or emotional instruction or encouragement. They also needed or wanted to be able to collect information and to consider and evaluate different options, which could be used to improve how they implement their ideas (Apilo et al., 2007).

In this paper, the processes and models used to consider and evaluate different options was based upon the processes and models used by Bitran and Pedrosa (1998), which are based upon the concept of linked stages in processes and models that all focus on developing a core set of ideas related to a specific product. In this paper, all of the stages in the processes and models were linked and all of the stages in the processes and models focused on developing a core set of ideas related AR mobile wellness devices and applications.

\subsection{Limitations}

The primary limitation of the processes and models used in this paper was related to the fact that the experimental subjects always evaluated their own ideas (either individually or in small groups). They did not evaluate the ideas that were developed by other individuals in other groups. Therefore, the processes and models used in this paper could be improved by including external evaluations into the processes and models. In addition, the experimental subjects used clay or paper models in the role playing dialog sessions. Complete working prototypes were not developed, used, or evaluated. The experimental subjects mentioned the limitation. Many said that they thought or felt that they wanted to see their ideas actually implemented. Some said that "It would be good to develop concrete images or actual devices which could be used to develop improvements or additional features. However, the process is a good beginning, because the processes are only limited by your own creativity". The limited time available for the processes and therefore the small number of experimental subjects that could participate in the processes were also a limitation, which may have affected the results. Consequently, the processes could also be improved by increasing the time used to complete the processes and the number of experimental subjects (or actual lead users) that participate in the processes. 


\section{Conclusions and future work}

The primary research contribution of this paper is new knowledge and understanding about users as designers, which was used to develop new digital human experience models. The new digital human experience models were used to improve the user-centred design processes used to develop AR mobile wellness devices and applications. The new digital human experience models were used to determine user requirements or needs for AR mobile wellness devices and applications, which designers can use to develop more useful, usable and successful AR mobile wellness devices and applications. The AR mobile wellness devices can also be used to improve users' experiences when using AR mobile wellness devices and applications. Consequently, this paper also improved both the digital human experience models that are used to develop AR mobile wellness devices and applications and the digital human experience models that are used by AR mobile wellness devices and applications. The results can be used as a foundation for future studies on digital human experience models for AR mobile wellness devices and applications, or other devices and applications. The results can also be used to develop and evaluate actual working prototypes of AR mobile wellness devices and applications, or other devices and applications.

The results showed that the concept of users as designers (in a primary enquiry, focus group meetings, role playing dialog sessions and a final evaluation enquiry) can be used to develop a rich set of ideas related to AR mobile wellness devices and applications. The results showed that the experimental subjects enjoyed the participatory product development process. The results showed that the experimental subjects would like to expand the product design process to include developing and evaluating actual working prototypes, which could be achieved, with more time and resources. The results also showed that the experimental subjects needed or wanted AR mobile wellness devices and applications that are more playful and fun to use than the textual visually overwhelming devices that are currently on the market. The experimental subjects wanted or needed AR mobile wellness devices and applications that have several key features: virtual reality displays, professional health and well-being advice, automation, communication and information sharing, motivation, nutritional information, calendars and schedules, training support and games. Therefore, providing the broad range of features appears to be the greatest challenge for product developers. Future work is needed to extend, enrich and refine the digital human experience models used to develop AR mobile wellness devices and applications and to extend, enrich and refine the digital human experience models that are used by AR mobile wellness devices and applications. In particular, the processes used to transfer information from one person to another person can be further improved. Many of the experimental subjects thought or felt that the requirements or needs for the AR mobile wellness devices and applications needed to be more fully defined or completely defined by the end of the processes. The results showed that the processes enhanced the experimental subjects' creativity, involvement and satisfaction. Most of the experimental subjects' thought or felt that they were 'getting what they wanted or needed'. However, the results also showed that the experimental subjects wanted to develop, use and evaluate actual working prototypes. Consequently, future work will focus on developing actual working prototypes of digital human experience models and using the prototypes to develop working software applications. 


\section{Acknowledgements}

I would like to thank all of the participants that contributed to this research. I would like to express my special thanks to Thomas Olsson and Kaisa Väänänen-Vainio-Mattila for giving me the opportunity to do this research as part of the DIEM project. I would also like to offer my special thanks to my work friends Else Lagerstam and Tomi Haustola. I am particularly grateful for the opportunity to work as a researcher in the Tampere University of Technology Unit of Human-Centred Technology and to participate in the devices and interoperability ecosystem, mobile MR (DIEM) project.

\section{References}

Adams, T. (2003) 'The power of perceptions: measuring wellness in a globally acceptable, philosophically consistent way', Wellness Management [online] http://www.kneipp.com/ kneipp_philosophy.html (accessed 15 December 2013).

Ahtinen, A., Isomursu, M., Huhtala, Y., Kaasinen, J., Salminen, J. and Häkkilä, J. (2008) 'Tracking outdoor sport - user experience perspective', Aarts, E. et al. (Eds.) AmI 2008, pp.192-209, LNCS5355, Springer-Verlag, Berlin, Heidelberg.

Albaum, G. (1997) 'The Likert scale revisited: an alternate version. In Market Research Society', Journal of the Market Research Society, Vol. 39, No. 2, pp.331-348.

Annesi, J.J. (1998) 'Effects of computer feedback on adherence to exercise', Perceptual and Motor Skills, Vol. 87, No. 2, pp.723-730.

Apilo, t., Takinen, T. and Salkari, I. (2007) Johda Innovaatioita, Publihed Talentum, Helsinki Finland.

Arrow, K.J. (1962) 'The economic implications of learning by doing', Review Economic Studies, Vol. 29, pp.155-173.

Azuma, R. (1997) 'A survey of augmented reality', In Presence: Teleoperators and Virtual Environments, Vol. 6, No. 4, pp.355-385.

Binder, T. (1999) 'Setting the stage for improvised video scenarios', In the Extended Abstracts of CHI 99 Conference, pp.230-231, ACM Press, Pittsburg, USA.

Bitran, G. and Pedrosa, L. (1998) 'A structured product development perspective for service operations', European Management Journal, Vol. 16, No. 2, pp.169-189.

Brandt, E. and Grunnet, C. (2000) 'Evoking the future: drama and props in user centred design', Proc. Participatory design Conference (PDC'00), pp.11-20, New York.

Buchenau, M. and Suri, J.F. (2000) 'Experience prototyping', Proc. DIS 2000, New York, ACM Press, pp.423-433 [online] http://ideodesign.com.au/images/uploads/news/pdfs/ FultonSuriBuchenau-Experience_PrototypingACM_8-00.pdf (accessed 15 December 2013).

Damodaran, L. (1996) 'User involvement in the system design process - a practical guide for users', In Behaviour and Information Technology, Vol. 15, pp.262-377.

Davis, M. (2003) 'Theoretical foundations for experiential systems design', In ETP'03, 7 November, Berkeley, California USA [online] http://fusion.sims.berkeley.edu/garagecinema/ pubs/pdf/pdf_68759352-c9fb-47dc-86969ff3ce864a71.pdf (accessed 15 December 2013).

Dewey, J. (1980) Art as Experience, p.355, Reprint, Perigee, New York.

Forlizzi, J. and Ford, S. (2000) 'The building blocks of experience in interactive systems', Proc. Designing Interactive Systems: Processes, Practices, Methods and Techniques, pp.419-423, New York NY, USA.

Herbs, I., Braun, A-K., McCall, R., Broll, W. (2008) 'TimeWrap: interactive time travel with a mobile mixed reality game', MobileHCI 2008, 2-5 September, Amsterdam, the Netherlands. 
Höysniemi, J., Aula, A., Auvinen, P., Hännikäinen, J. and Hämäläinen, P. (2004) 'Shadow Boxer a physically interactive fitness game', NordiCHI '04, pp.23-24, Tampere, Finland.

Iacucci, G., Kuutti, K. and Ranta, M. (2000) 'On the move with a magic thing: role playing in concept design of mobile services and devices', Proc. DIS 2000, ACM Press, pp.193-202 [online] http://citeseerx.ist.psu.edu/viewdoc/download?doi=10.1.1.22.4404\&rep=rep1\& type $=$ pdf (accessed 15 December 2013).

Kitzinger, J. (1995) 'Qualitative research: introducing focus groups', British Medical Journal, Vol. 311, pp.299-302.

Lämkull, D., Hanson, L. and Ortengren, R. (2009) 'A comparative study of digital human modeling simulation results and their outcomes in reality: a case study within manual assembly of automobiles', International Journal of Industrial Ergonomics, Vol. 39, No. 2, pp.428-441.

Laverie, D.A. (1998) 'Motivations for ongoing participation in fitness activity', Leisure Sciences Vol. 20, pp.277-302.

Leslie, E., Owen, N., Salmon, J., Bauman, A. and Kai Lo, S. (1999) 'Insufficiently active Australian college student: perceived personal, social and environmental influences', Preventive Medicine, Vol. 28, pp.20-27.

Likert, R. (1932) 'A technique for the measurement of attitudes', Archives of Psychology, New York, Vol. 140, pp.1-55.

Locke, E.A. and Latham, G.P. (1985) 'The application of goal setting to sports', Journal of Sport \& Exercise Psychology, Vol. 7, No. 3, pp.205-222.

Maguire, M. (2001) 'Methods to support human-centred design', International Journal of HumanComputer Studies, Vol. 55, pp.587-634 [online] http://www.cse.chalmers.se/research/group/ idc/ituniv/courses/06/ucd/papers/maguire\%202001a.pdf (accessed 15 December 2013).

Martin, J.E., Dubbert, P.M., Katell, A.D., Thompson, J.K., Raczynski, J.R., Lake, M., Smith, P.O., Webster, J.S., Sikora, T. and Cohen, R.E. (1984) 'Behavioral control of exercise in sedentary adults: studies 1 through 6', Journal of Consulting and Clinical Psychology, Vol. 52, No. 5, pp.795-811.

Merton, R., Fisk, M. and Kendall, P. (1956) The Focused Interview: A Report of the Bureau of Applied Social Research, Columbia University, New York.

Morgan, D. (1988) Focus Groups as Qualitative Research, Sage, London, England.

Müller, H. and Lanz-Kaufmann, E. (2001) 'Wellness tourism: market analysis of a special health tourism segment and implications for the hotel industry', Journal of Vacation Marketing, Vol. 7, No. 1, pp.5-17.

Myers, J.E., Sweeney, T.J. and Witmer, J.M. (2000) 'The wheel of wellness counseling for wellness: a holistic model for treatment planning', Journal of Counseling \& Development, Vol. 78, pp.251-266.

Nahrstedt, W. (2004) 'Wellness: a new perspective for leisure centers, health tourism and spas in europe on the global health market', Weiermair, K. and Mathies, C. (Eds.): The Tourism and Leisure Industry: Shaping the Future, pp.181-198, The Haworth Hospitality Press, Bringhamton (NY).

Nauman, A. and Rötting, M. (2007) 'Digital human modeling for design and evaluation of human-machine systems', in MM_Interaktiv, No. 12, pp.27-35 [online] http://www.mmiinteraktiv.de/uploads/media/04-Naumann_Roetting.pdf (accessed 15 December 2013).

Nielsen, J. (1993a) Usability Engineering, Academic Press, Boston, United State.

Nielsen, J. (1993b) Usability Engineering, pp.299-302, Morgan Kaufmann, San Diego, CA.

Olsson, T., Väänänen-Vainio-Mattila, K., Ihamäki, P., Lagerstam, E. and Olkkonen-Ventä, L. (2009) 'User expectations for mobile mixed reality services', ECCE 2009, European Conference on Cognitive Ergonomics, 30 September-2 October, Otaniemi, Helsinki.

Paschali, A.A., Goodrick, G.K., Anastasia, K. and Papadatou, D. (2005) 'Accelerometer feedback to promote physical activity in adults with type 2 diabetes: a pilot study', Perceptual and Motor Skill, Vol. 100, pp.61-68. 
Peat, H.J. and Willett, P. (1991) 'The limitations of term co-occurrence data for query expansion in document retrieval systems', Journal of the American Society for Information Science, Vol. 42, No. 5, pp.378-383.

Poon, A. (1993) Tourism, Technology and Competitive Strategies, CAB-International, Wallingford, UK.

Preece, J., Rogers, Y., Sharp, H., Beyon, D., Holland, S. and Carey, T. (1994) Human-Computer Interaction, Addison-Wesley, Reading, MA.

Reddy, M. (1993) 'The conduit metaphor: a case of frame conflict in our language about', in Ortony, A. (Eds.): Metaphor and Thought, pp.164-201, Cambridge University Press, Cambridge England, New York.

Sanders, E.B.N. (2001) 'Virtuosos of the experience domein', Proc. IDSA Education Conference, URI [online] http://www.maketools.com/pdfs/VirtuososoftheExperienceDomain_ Sanders_01.pd f(accessed 15 December 2013).

Seland, G. (2006) 'System designer assessments of role play as a design method: a qualitative study', NordiCHI 2006: Changing Roles, 14-8 October, Oslo, Norway.

Svanaes, D. and Seland, G. (2004) 'Putting the user center stage: role playing and low-fi prototyping enable end users to design mobile systems', CHI 2004, 24-29 April, Vienna, Austria.

Träskbäck, M. (2004) User Requirements and Usability of Mixed reality Application, Licentiate thesis, Software Business and Engineering Laboratory, Department of Computer and Engineering, Helsinki University of Technology, Finland.

Uematsu, Y. and Saito, H. (2008) 'Visual enhancement for sport entertainment by vision-based augmented reality', in Advanced in Human-Computer Interaction [online] http://www.hindawi.com/journals/ahci/2008/145363/ (accessed 15 December 2013).

Varela, F.J. (1999) 'The specious present: a neurophenomenology of time consciousness', in Petitot, J., Varela, F.J., Pachoud, B. and Roy, J-M. (Eds.): Naturalizing Phenomenology: Issues in Contemporary Phenomenology and Cognitive Science, pp.266-314, Stanford University Press, Stanford, California.

von Hippel, E. (1998) 'Economics of product development by users: the impact of 'sticky' local information', Management Science, Vol. 44, No. 5, pp.629-644.

Weiermair, K. (2001) 'Neue Organisations-, Koordinations- und Führung- sprinzipien im Alpinen Tourismus (New forms of organisation, coordination and leadership in alpine tourism)', in Weiermair, K., Peters, M. and Reiger, E. (Eds.) Vom Alten zum Neuen Tourismus: Beiträge aus Forschung und Praxis (From the Old Tourism to the New Tourism: Contributions from Research and Practice), pp.108-117, Studiaverlag, Innsbruck, Austria.

Yang, G.C. and Yacoub, M. (2006) Body Sensor Networks, Springer-Verlag, London, UK. 